\title{
Grid-Connected Rectifier Based Dynamic Voltage Restorer To Improve Power Quality By Compensating Voltage Sag And Swell
}

\author{
Someshwara Thota $^{1}$, Vinay Kumar Awaar ${ }^{1 *}$, Praveen Jugge ${ }^{1}$, and Tara Kalyani $\mathrm{S}^{2}$ \\ ${ }^{1}$ Department of EEE, GRIET, Hyderabad, India \\ ${ }^{2}$ Professor, JNTUH, Department of EEE, JNTUH, Hyderabad, India
}

\begin{abstract}
Voltage sag and voltage swell are frequently occurred power quality problems in present power distribution system, which are cause more problems to avoid these problems and maintain constant voltage at sensitive load during sag and swell Dynamic voltage restorer gives solution .we propose self-supported DVR, to minimize the cost by preventing external dc source in DVR, it is controlled by SRF PI control along with an inner current loop to stabilize the system and outer voltage loop to increase the system robustness. The proposed model provides fast voltage restoration for a short and long duration of voltage sags and swells manage wide load current variation for short and long voltage disturbances. In this paper, we present the effectiveness of the proposed method by using MATLAB/simulation results. A laboratory prototype DVR is modelled and we are using CCS studio to interface DSPTMS320F28027F
\end{abstract}

\section{Introduction}

Power quality problems are classified based on quantity into voltage power quality and current power quality problems. Voltage power quality problems are classified as voltage sag, swell, interruption and voltage notch depending on magnitude variation of quantity [1-3]. The load connected to the power system is dynamic; when the load connected to the system is increased, it causes voltage sag and the load connected to the system decreases it causes voltage swell. During voltage sag and swell, the voltage across the load is not constant or rated due to these more problems that occur; the uneven operation of end-user equipment, cause production losses of process industries, and maloperation of relays and circuit breaker. The custom power devices STATCOM (static compensator), DVR (dynamic-voltage restorer) and UPQC (unified power quality controller) provide rated voltage across the load even voltage sag and swell occur. Still, the complexity of design and installation cost industries prefer DVR more than STATCOM and UPQC [3-7]. Dynamic voltage restorer is a series compensating device. It injects the voltage in series with the line; DVR injects voltage in phase and out of phase with supply voltage during voltage sag and voltage swell. To inject the voltage, DVR needs a certain amount of real and reactive power [8-13]; it is provided by using an energy source in DVR. Depending on the energy source, DVR is classified as capacitor-supported DVR, battery-supported DVR and Rectifier-supported DVR. The large magnitude and long duration sag condition require a large amount of energy storage capacity, increasing device cost. For avoiding high price for designing of DVR, we propose a self or grid-connected rectifier-supported DVR to compensate voltage sag and voltage swell [14-16], which is controlled by using SRF PI controller along with inner current loop it stabilizes the system and outer voltage loop it increases the robustness of the system. The proposed model provides fast restoration and reduces voltage disturbances. The proposed method can manage wide load current variations and avoids current distortions during short, fast and long 
voltage variations [17-21]]. The effectiveness of these control methodology DVR is verified by using simulation studies. A laboratory prototype DVR is modelled and we are using DSPTMS320F28027F and CCS software to real-time interface platform. In fig:1 shows a block diagram of self or grid-connected rectifier-supported dynamic voltage restorer.

It contains mainly rectifier, inverter and injection transformer. The rectifier is a converter that converts ac supply to dc supply; the rectifier may be a controlled type or uncontrolled type. Mostly controlled type rectifier is used due to the controlling nature of its operation. The output voltage of the controlled rectifier is expressed as,

$V_{d c}=\frac{2 V_{m}}{\Pi} \cos \alpha$

$\mathrm{V}_{\mathrm{m}}=$ peak magnitude of supply voltage

$\mathrm{V}_{\mathrm{dc}}=$ rectifier output voltage

An inverter is a converter that converts dc supply to ac supply; it is mainly classified as VSI (voltage source inverter) and CSI (current source inverter). VSI has more advantages than CSI mostly used VSI. An inverter is controlled by using PWM (pulse width modulation) technique and which are various types depending on the reference signal. In the proposed model, we are using SPWM (sinusoidal pulse width modulation)

$$
V_{i n v}=m V_{d c}
$$

$\mathrm{V}_{\mathrm{dc}}=$ Rectifier output voltage(or) inverter input voltage $\mathrm{m}=$ modulation index

$\mathrm{V}_{\text {inv }}=$ inverter output voltage

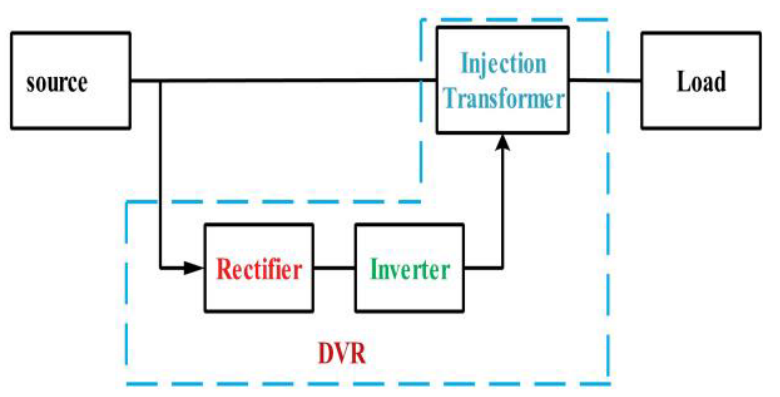

Figure.1.block diagram of grid-connected rectifier-supported DVR

An injection transformer is used to inject voltage in series with the line by connecting it in series. We connect a filter circuit between an injection transformer and an inverter to filter out harmonics in injected voltage. The filter circuit can be connected either at the primary side of the injection transformer or at the secondary side. The primary side connection has more advantages than the secondary connection [22].

$$
V_{\text {load }}=V_{\text {supply }} \pm V_{D V R}
$$

\section{Control methodology}

In this paper, we propose an SRF PI controller along with an inner current loop to stabilize the system and outer voltage loop to increase the system robustness to control the DVR and to maintain constant dc voltage at inverter input even disturbances occur in grid voltage we use two PI controllers in the control circuit of the rectifier.

In the DVR controller, initially, we are taking load voltage as $\alpha$-component of load voltage and provide 90 degrees delay to load voltage to get $\beta$-component of load voltage and converted this $\alpha, \beta$ component of load voltage into $d-q$ components of load voltage and compare it with reference voltage $d-q$ components apply the result of the comparison to PI controllers and provide feedback with inverter filter capacitance and load voltage $\mathrm{d}-\mathrm{q}$ components to minimize the error. After PI controller, we get d-q components of current, again converts $\mathrm{d}-\mathrm{q}$ components of currents into $\alpha, \beta$ of current, now compare $\alpha$-component of

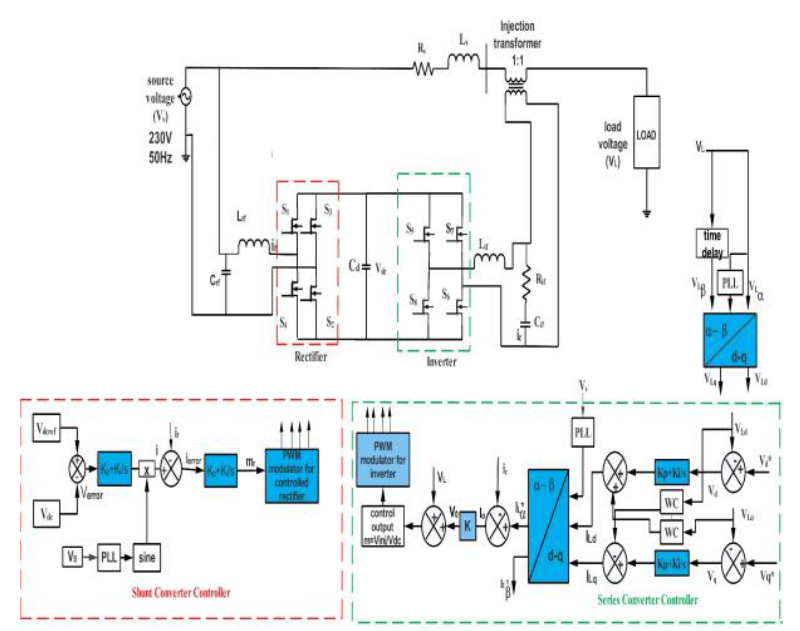

Figure.2. block diagram of the proposed controlled methodology

current with filter capacitor current, now applying the result of the comparison is passed through $\mathrm{P}$ controller, now add load voltage result of above addition we get reference signal to PWM and generate pulses to inverter switches.

For controlling rectifier to maintain constant dcvoltage during sag and swell conditions in these firstly compare reference dc voltage with rectifier output voltage apply error of comparison to PI controller and multiply sine of the phase of grid voltage by using PLL after that we compare it with rectifier input current, after passing it through PI controller from second PI controller we are getting reference voltage to PWM and getting pulses to rectifier switches.

$\mathrm{L}_{\mathrm{rf}}$ rectifier filter inductance, $\mathrm{C}_{\mathrm{d}}$ is a common dc-link capacitor, $\mathrm{V}_{\text {in }}$ is the input voltage to the rectifier.

The shunt converter maintains the dc-link voltage constant during voltage sag and swell compensation. 
The dc-link voltage is sensed with the help of a voltage sensor. The output of the voltage controller is compared with the shunt converter inductor current to generate a reference signal. This reference signal maintains a constant dc-link voltage.

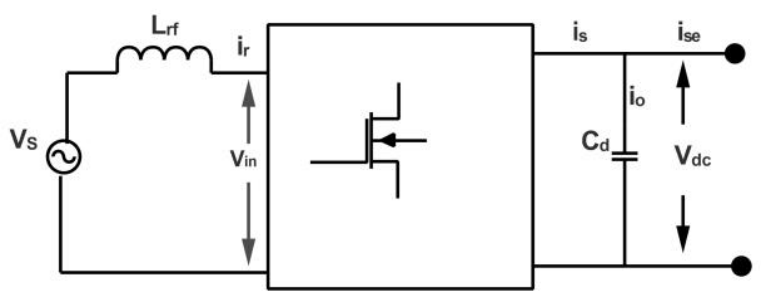

Figure.3. Equivalent circuit representation of shunt converter

$$
G_{i s h}(S)=\frac{i_{r}(s)}{V_{i n}(s)}=-\frac{1}{s L r f}
$$

The plant transfer function of the shunt converter outer control loop is given by

$G_{v s h}(S)=\frac{V_{d c}(s)}{i_{0}(s)}=\frac{1}{s C d}$

Considering the effect of time delay, PI controller and dynamics of the inner current controller. The linearized relation between vin and vdc is given as follows:

\section{$V_{\text {in }}(S)=m_{r} V d c$}

(6)

where $\mathrm{mr}$ is shunt converter modulation index from (4)- (6), the relation between io and ir is given by

$$
\frac{i_{0}}{i r}=-\frac{S C_{d}}{m_{\gamma} S L r f}
$$

The relation among $i_{s}, i_{o}$ and $i_{\text {se }}$ is given by $i_{s}(s)=i_{s e}(s)+i_{0}(s)$

Taking $i_{\text {se }}$ as disturbance input, the relation between is and $i_{r}$ is

$$
\frac{i_{s}(s)}{i r(s)}=-\frac{S C_{d}}{m_{\gamma} S L r f}
$$

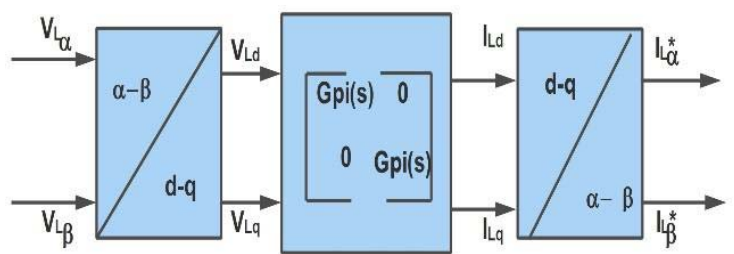

Figure.4. block diagram representation of SRF PI controller

The above fig indicates the SRF PI control methodology used to control the DVR; the complete transfer function of the methodology is derived in [21]

\section{Simulation results}

The proposed model is implemented in MATLAB/SIMULINK software and tested for various sag and swell conditions which are $10 \%, 20 \%, 30 \%, 40 \%$ and $50 \%$, and getting results with accurate and in an acceptable range. The suggested control strategy of single-phase SRFPI is applied for the DVR system consisting of a VSI of $0.5 \mathrm{kVA}$. The system is successfully simulated, and the hardware prototype was developed. Below we represent the waveforms of $40 \%$ sag and the swell condition is applied to load having the resistances of $400 \mathrm{ohm}$ and inductances of $150 \mathrm{mH}$. The shunt converter has filter values $\mathrm{R}=5 \Omega, \quad \mathrm{L}=1000 \mathrm{mH}, \mathrm{C}=10 \mu \mathrm{F}$ and series converter have $\mathrm{R}=15 \Omega, \mathrm{L}=10 \mathrm{mH}, \mathrm{C}=20 \mu \mathrm{F}$ filter values. The shunt and series converter controller having current loop PI controller values $\mathrm{KP}=0.1$, $\mathrm{KI}=120$ and $\mathrm{KP}=0.5, \mathrm{~K}_{\mathrm{I}}=60$, voltage loop PI controller values $\mathrm{K}_{\mathrm{P}}=0.1, \mathrm{~K}_{\mathrm{I}}=120$ and $\mathrm{K}_{\mathrm{P}}=0.5$. 

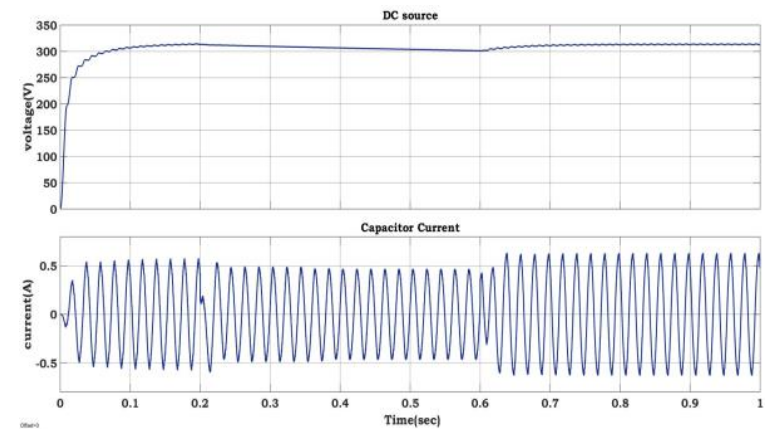

Figure 5 wave forms of DC source and inverter filter capacitor current in sag condition

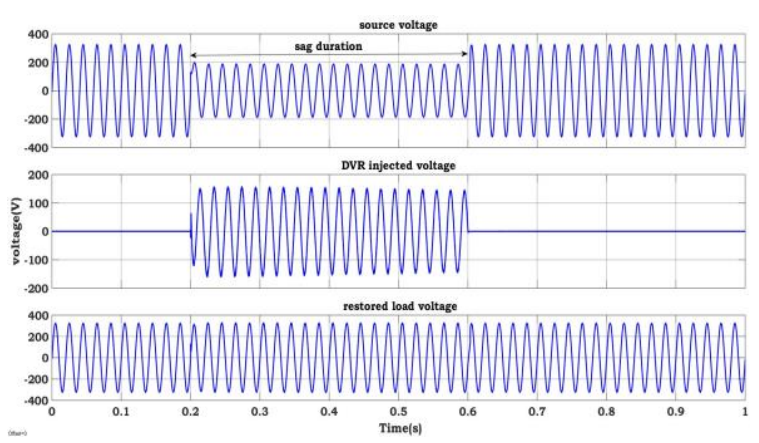

Figure 6. voltage wave forms of source, DVR and load during sag condition

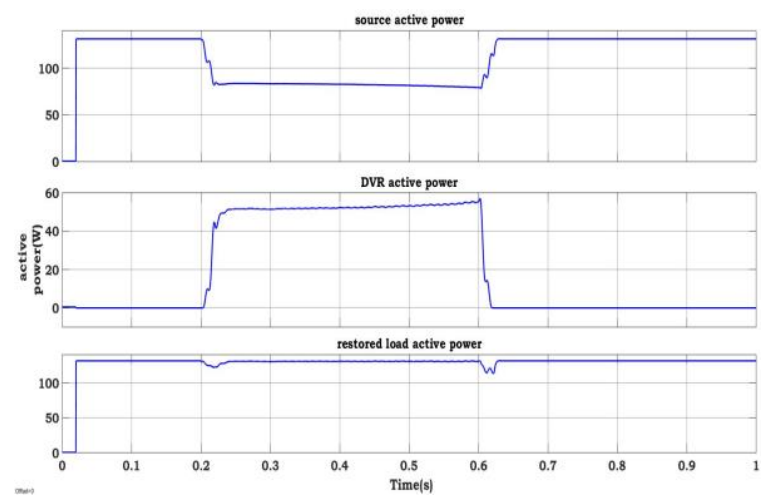

Figure 7 active power wave forms of source, DVR and load during sag condition

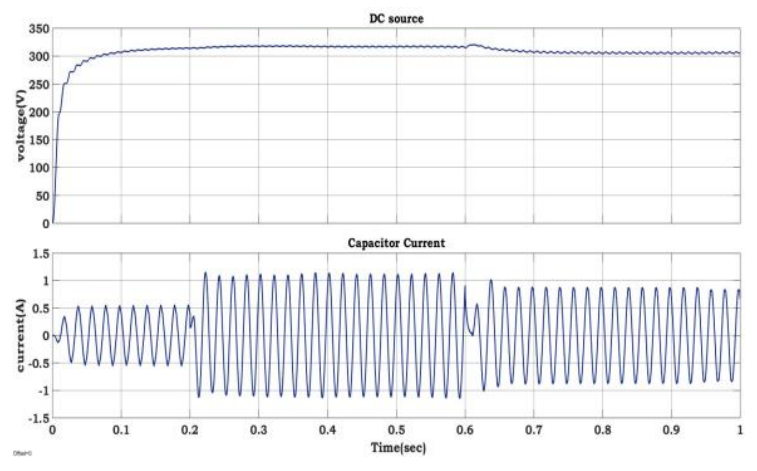

Figure 8. wave forms of DC source and inverter filter capacitor current in swell condition

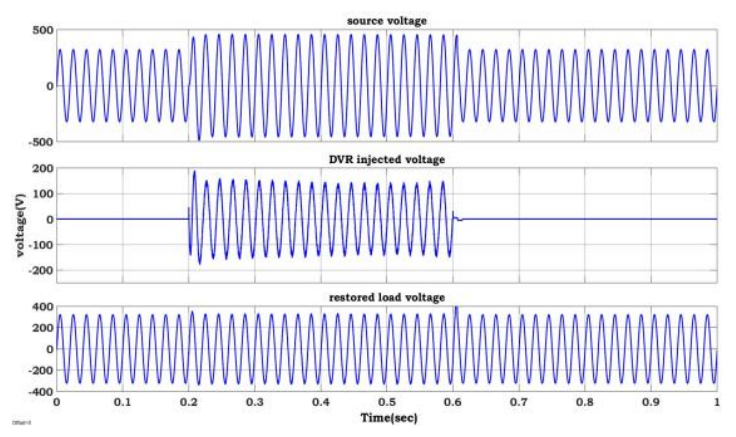

Figure 9. voltage wave forms of source, DVR and load during swell condition

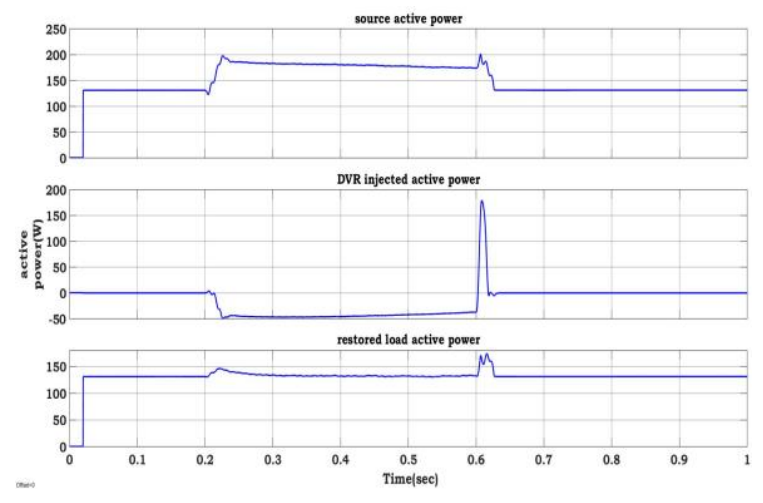

Figure 10. active power wave forms of source, DVR and load during swell condition 


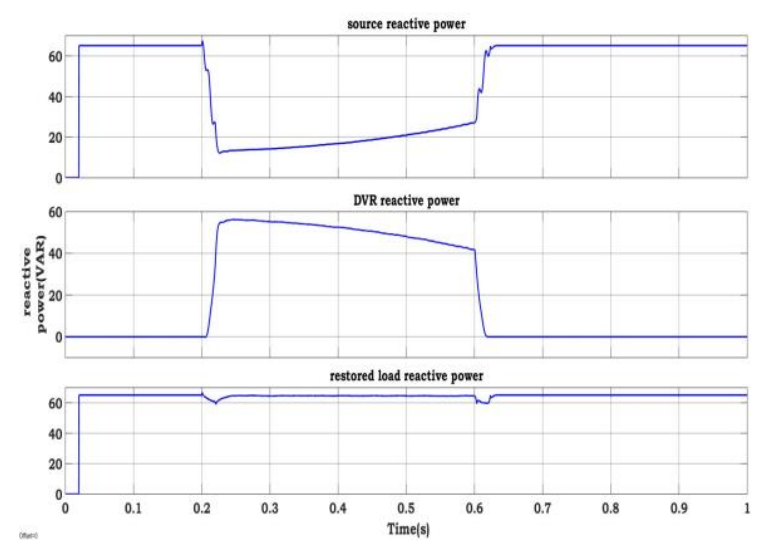

Figure.11. reactive power wave forms of source, DVR and load during sag condition

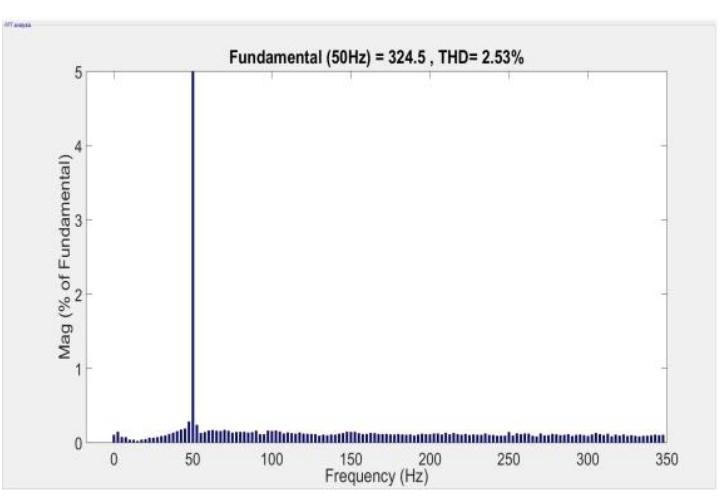

Figure .13.THD of load voltage during sag duration

Table 1. voltage, active and reactive powers during sag condition

\begin{tabular}{|c|c|c|c|c|c|c|c|c|c|}
\hline \multirow{2}{*}{$\begin{array}{r}\text { Para } \\
\text {-meter }\end{array}$} & \multicolumn{3}{|c|}{ Before Sag } & \multicolumn{3}{c|}{ During Sag } & \multicolumn{3}{c|}{ After Sag } \\
\cline { 2 - 10 } & $\mathrm{V}$ & $\mathrm{P}$ & $\mathrm{Q}$ & $\mathrm{V}$ & $\mathrm{P}$ & $\mathrm{Q}$ & $\mathrm{V}$ & $\mathrm{P}$ & $\mathrm{Q}$ \\
\hline Source & 230 & 131 & 65 & 133 & 82 & 21 & 230 & 131 & 65 \\
\hline DVR & 0 & 0 & 0 & 97 & 50 & 45 & 0 & 0 & 0 \\
\hline Load & 230 & 131 & 65 & 229 & 131 & 65 & 230 & 131 & 65 \\
\hline
\end{tabular}

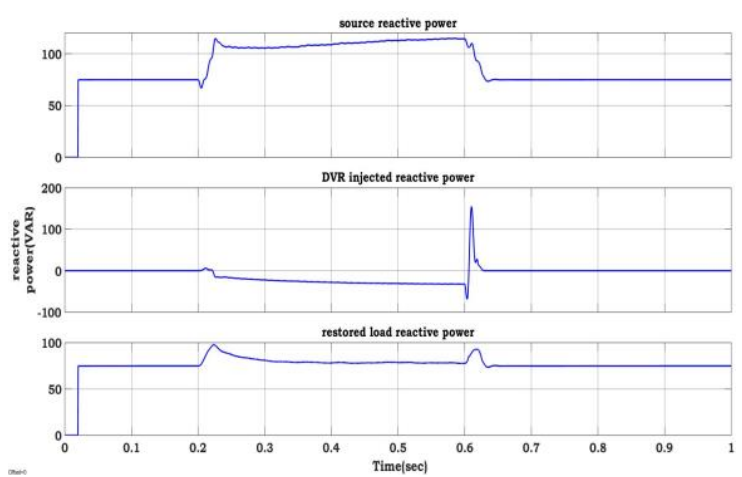

Figure.12.reactive power wave forms of source, DVR and load during swell condition

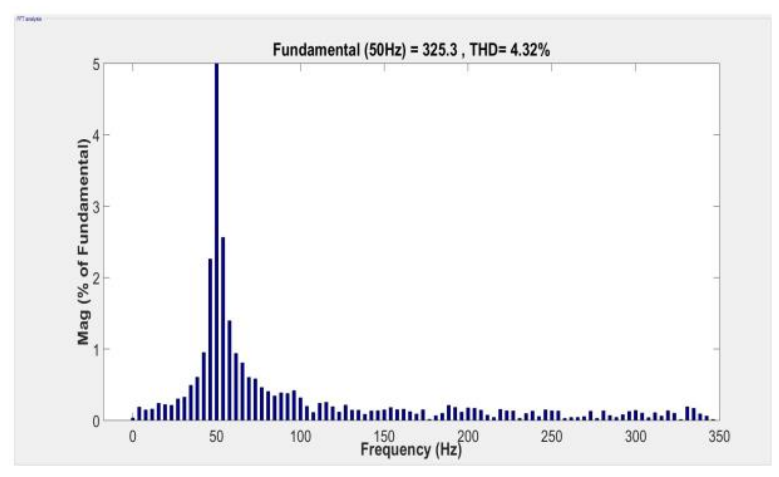

Figure 14 THD of load voltage during swell duration

Table 2. voltage, active and reactive powers during swell condition

\begin{tabular}{|l|c|c|c|c|c|c|c|c|c|}
\hline \multirow{2}{*}{$\begin{array}{c}\text { Para - } \\
\text { meter }\end{array}$} & \multicolumn{3}{|c|}{ Before Swell } & \multicolumn{3}{c|}{ During Swell } & \multicolumn{3}{c|}{ After Swell } \\
\cline { 2 - 10 } & V & P & Q & V & P & Q & V & P & Q \\
\hline Source & 230 & 131 & 65 & 322 & 185 & 84 & 230 & 131 & 65 \\
\hline DVR & 0 & 0 & 0 & 91 & 53 & 18 & 0 & 0 & 0 \\
\hline Load & 230 & 131 & 65 & 231 & 132 & 66 & 230 & 131 & 65 \\
\hline
\end{tabular}


In figure 5, the dc source for inverter or rectifier output waveform input to the rectifier is the grid voltage having a magnitude of $325 \mathrm{~V}$ during the sag period. It drops to $190 \mathrm{~V}$, but the output of the rectifier before after sag condition is $312 \mathrm{~V}$. We maintain nearly constant during sag $308 \mathrm{~V}$ using proper controller during sag condition as before and after sag condition.

In figure 6, During sag condition, the source voltage drops to $133 \mathrm{~V}$, but the DVR injects the $97 \mathrm{~V}$, so across the load, we obtain $229 \mathrm{~V}$

In figure 7 Active power of the source drops to $82 \mathrm{~W}$ during sag duration. DVR injects the active power of $65 \mathrm{~W}$ in sag duration, so across the load, we maintain rated active power.

In figure 8 , the dc source for inverter or rectifier output waveform input to the rectifier is the grid voltage having a magnitude of $325 \mathrm{~V}$ during the swell period it rises to $450 \mathrm{~V}$. Still, the output of the rectifier before and after the swell condition is $312 \mathrm{~V}$. During sag $316 \mathrm{~V}$, using proper controller during swell condition also maintain nearly constant as before and after swell condition

In figure 9, During swell conditions, the source voltage is increased to $322 \mathrm{~V}$, but the DVR injects with opposite phase $91 \mathrm{~V}$, so across the load, we obtain $231 \mathrm{~V}$.

In figure 10 , Before and after swell duration active power of source and load having rated value is $131 \mathrm{~W}$. During swell duration, source active power increases to $185 \mathrm{~W}$, DVR injects $53 \mathrm{~W}$ with opposite phase, across the load maintain the $132 \mathrm{~W}$.

In figure 11, The reactive power of the source drops to 16VAR during sag condition, DVR injects 50VAR in sag duration, so across the load, we obtain the rated reactive power of $65 \mathrm{VAR}$. DVR injects the required amount of voltage, active and reactive power to maintain the rated values, Across the load.

In figure 12, Before and after swell duration, the reactive power of source and load is 65VAR. During swell source reactive power increases to 85VAR, DVR injects 18VAR with opposite phase and maintains 66VAR across the load.

In fig 13, THD of load voltage in sag condition during sag duration is $2.53 \%$, before and after sag duration is nearly zero.

In fig14 the THD of load voltage during swell conditions is $4.32 \%$, before and after swell duration is nearly zero

In Table 1 and 2 shows the active, reactive power and voltage at various source, DVR, and load conditions. During disturbances voltage, active and reactive powers of the source are changes but load voltage, active and reactive power values are not changes because, during the disturbances, DVR inject voltage, active and reactive powers in phase or out of phase depending on disturbance, due to DVR operation we are getting constant supply across the load even if a disturbance occurs in supply.

\section{Conclusions}

The proposed Energy mitigate compensation technique for dynamic voltage restorer to mitigate voltage sags and voltage swells are verified in MATLAB/SIMULINK getting satisfactory results and hardware implementation of the proposed model is developed for sag condition. The compensation of voltage across the load during both sag and swell period occurs instantaneously within $1 \mathrm{~ms}$, and restoration of active and reactive power across the load in both sag and swell period is within $30 \mathrm{msec}$. In [3] authors are proposed the discrete wavelet transform using passive LC filters for operating DVR, in these the restoration of voltage is takes place in $5 \mathrm{~ms}$ and in [18] authors are proposed a hybrid detection method to control the DVR, in these the restoration of voltage is takes place within $2 \mathrm{~ms}$ but in my proposed algorithm the restoration of voltage takes place within $1 \mathrm{~ms}$. In [11] authors are proposed the P-Q theorycontrolled DVR, in these the active power restoration is takes place in $80 \mathrm{~ms}$ but by using proposed algorithm the restoration of active power takes place within $30 \mathrm{~ms}$. The proposed model is very reliable for long duration and large magnitudes of sag and swells durations. \% THD values of load voltage and current is within tolerable limits.

\section{References}

[1]. R. Zhang, M. Cardinal, P. Szczesny and M. Dame, in $33^{\text {rd }}$ annual IEEE PESC (2002).

[2]. V. Khadkiksr, A. Chadra and B.N. Singh in IET Power Electronics, 2(1), 67 (2009).

[3]. S.A. Saleh, C.R. Moloney and M.A. Rahman, in IEEE TPD, 23(4,)2366 (2008).

[4]. Awaar. Vinay Kumar, Jugge. Praveen and S. Tara Kalyani, J of Con. Auto. and Ele. Sys., (2019).

[5]. S.S. Rao, P.S.R. Krishna and S. Babu, in ICAMMAET, (2017).

[6]. T.L. Ilamkar and V. Joshi, in ICCTCT, (2018).

[7]. M. Farhadi-Kangarlu, E. Babaei and F. Blaabjerg, in IJ EPES, (2017).

[8]. Saeed. Golestan, Mohammad. Monfared, M. Josep and Mahmood. Joorabian, in $2^{\text {nd }}$ PEDSTC, (2011).

[9]. N.H. Woodley IEEE PESWMC,4 (2010).

[10].D.N. Katole, M.B. Daigavane, S.P. Gawande and P.M. Daigavane, IEEE ICPEDES, (2018). 
[11]. D.N. Katole, M.B. Daigavane, S.P. Gawande and P.M. Daigavane, IEEE ICPEDES, (2018).

[12].Awaar. V.K and Jugge. P, Advances in EEE,13(2), 107 (2015).

[13]. K. Piatek, IEEE $12^{\text {th }}$ International PEMCC, (2006).

[14]. C. Meyer, C. Romaus and R.W. Dedoncker, in IEEE $36^{\text {th }}$ PESC, (2005).

[15]. C.N.M. Ho and S.H. Chung, in IEEE PESC, (2008).

[16]. E. Babaei, M.F. Kangarlu and M. Sabahi, in IEEE TPD, 25(4), (2010).

[17].T. Jimichi, H. Fujita and H. Akagi, in IEEE TIA, 44(3),(2008).

[18].B. Bae, J. Jeong, J. Lee and B. Han, in IEEE TPD, 25(2), 1210(2010).

[19]. S. Subramanian and M.K. Mishra, in IEEE TPE, 25(2),514(2010).

[20].Hossein. Hafezi and Roberto. Faranda, in IEEE TPE, 33(9),(2018).

[21].Awaar. Vinay Kumar, Jugge. Praveen, S. Tara Kalyani and Thota. Someshwara, in IEEE SeFeT Con., (2021).

[22].Amit. Meena, Ahirazul. Islam, Sandeep Anand, Yogesh Sonawane and Tungare. Sanjay, (2017). 